\title{
Cannabinoids in Neuroinflammation, Oxidative Stress and Neuro Excitotoxicity
}

\section{Rosales-Corral $\mathbf{S}^{1 *}$, Hernández $\mathrm{L}^{2}$ and Gallegos $\mathbf{M}^{2}$}

${ }^{1}$ Neuroscience Division, Western Biomedical Research Center, Mexican Institute of Social Security, Guadalajara, Mexico

${ }^{2}$ Department of Physiology, University of Guadalajara Health Science Center, Guadalajara,Jalisco, Mexico

\begin{abstract}
Research on cannabinoids has been growing significantly in the last five years. More than fifty percent of this research corresponds to "cannabinoids and brain", particularly about neurodegeneration. In this sense, there is evidence reporting that specific phyto cannabinoids show some specific action on each one of main pathogenic mechanisms involved in neurodegeneration such as oxidative stress, neuroinflammation and excitotoxicity. However, by using the same targets, cannabinoids may also induce the opposite effects, this is, excitotoxicity and inflammation. In fact, both tetrahydro cannabinol and cannabidiol activate cannabinoid receptors, but they also may act as antagonists of those receptors. It seems to be a dose-dependent issue; nonetheless, as reviewed in this paper, many other factors such as timing, type of cell and its state of activity even the activation of different, noncannabinoid receptorsseem to have a role related to those unexpected antagonic effects.
\end{abstract}

Keywords: Cannabinoids; Neurodegeneration; Alzheimer; Excitotoxicity; Neuroinflammation

Abbreviations: CB1R: cannabinoid receptor type 1; CB2R: cannabinoid receptor type 2; PPARs: peroxisome proliferator activated receptors; TPRV1: transient receptor potential vanilloid transmittergated channels; CNS: central nervous system; ATP: adenosine triphosphate; NLRP3:nucleotide-binding domain; leucine-rich-repeatcontaining family; pyrin domain-containing 3; IL: interleukin; GPx: glutathione peroxidase; NADPH: nicotinamide adenine dinucleotide phosphate; $\mathrm{O}_{2}$-superoxide anion; $\mathrm{H}_{2} \mathrm{O}_{2}$ : hydrogen peroxide; $\mathrm{SO}$ : superoxide dismutase; $\mathrm{OH} \cdot$ : hydroxyl radicals; NO: nitric oxide; ONOO-:peroxynitrite anion; ROS: reactive oxygen species; GSH: reduced glutathione; GSSG: glutathione disulfide; NMDA: N-Methyl$\mathrm{D}$-aspartic acid; $\mathrm{IP}_{3}$ : inositol 1,4,5, triphosphate; TNF: tumor necrosis factor; AEA:anandamide; 2-arachidonylethanolamide (2-AG); 2-AGE: 2-Arachidonyl glyceryl ether; AD: Alzheimer disease; TBI: traumatic brain injury; GPRs: G protein coupled receptors; AMPA, a-amino-3-hydroxy-5-methyl-4-isoxazolepropionic acid receptor; THC: tetrahidro cannabinol; CBD: cannabidiol; CBN: cannabinol; CBC: Cannabichromen; CBG: Cannabigerol; VCAM-1: vascular cell adhesion molecule-1; NF-кB: nuclear factor kappa-B; PKA: protein kinase A; NOS: Nitric oxide synthase; FCCP: carbonyl cyanide-4(trifluoromethoxy) phenylhydrazine

\section{Introduction}

Cannabinoids are a class of signaling lipids consisting of amides and esters of long-chain polyunsaturated fatty acids synthesized by $\mathrm{Ca} 2+$ or G-protein-dependent processes from lipid precursors in plasma membranes and exert their actions by binding to receptors [1]. These receptors can be 7-transmembrane receptors $(\mathrm{CB} 1 \mathrm{R}, \mathrm{CB} 2 \mathrm{R}$, GPR18, GPR55 and GPR119), nuclear receptors (PPARa, PPAR $\beta / \gamma$ and PPAR $\gamma$ ) and the transient receptor potential vanilloid transmittergated channels (TPRV1) [2]. Primary effects are mediated by CB1R and CB2R, which are coupled to $G_{i}$ or $G_{o}$ protein, modulating negatively to adenylyl cyclase, therefore cannabinoids attenuate the production of the second messenger cyclic adenosine monophosphate (cAMP). $\mathrm{CB} 1 \mathrm{R}$ and $\mathrm{CB} 2 \mathrm{R}$ are also coupled to ion channels via $\mathrm{G}$ protein signal transduction pathways [3].

There is a long list of undesirable effects of cannabis going from acute effects such as, impaired short-term memory and attention, reduced motor skills, anxiety, panic, even psychotic symptoms, to chronic effects such as, addiction, or subtle impairments of attention and memory [4]. Indeed, cannabis use has been related to psychosis or schizophrenia [5]. Certain cannabinoids, on the other hand, may induce neuroprotective pathways either by using cannabinoid receptors or by interacting with other receptors, such as the peroxisome proliferator-activated receptors (PPARs), as mentioned before. In such a manner that cannabinoids could go further and become involved in the promotion of neural stem cell proliferation, either through CB2R [6], or by activating PPARs [7]. It is the purpose of this short review to analyze the role of cannabinoids in the three key aspects of neurodegeneration: oxidative stress, neuroinflammation and glutamate-induced excitotoxicity.

\section{Neuroinflammation, Oxidative Stress and Excitotoxicity in Neurodegeneration}

There is a sophisticated scheme of vigilance of the environment by astrocytes and microglia, which maintain simultaneously a precise communication with neurons through specific mediators. This isachieved through specific mediators, such as $\mathrm{Ca}^{2+}$, cytokines and a group of molecules known as damage-associated molecular patterns (DAMPs) acting as stimulators of the immune system, similar to pathogen-associated molecular patterns (PAMPs). In such a manner that astrocytes and neurons regulate the activity of microglia during neuroinflammatory processes, while astrocyte calcium waves may modulate neuronal activity [8]. Minimal alterations in the redox

*Corresponding author: Rosales-Corral S, Neuroscience Division, Western Biomedical Research Center, Mexican Institute of Social Security, Guadalajara, Mexico, Tel: (+52) 33-36170060; E-mail: espiral17@gmail.com.

Received February 05, 2015; Accepted February 23, 2015; Published March 03 2015

Citation: Rosales-Corral S, Hernández L, Gallegos M (2015) Cannabinoids in Neuroinflammation, Oxidative Stress and Neuro Excitotoxicity. Pharm Anal Acta 6 346. doi:10.4172/2153-2435.1000346

Copyright: () 2015 Rosales-Corral S, et al. This is an open-access article distributed under the terms of the Creative Commons Attribution License, which permits unrestricted use, distribution, and reproduction in any medium, provided the original author and source are credited. 
environment, or molecular alert signals modulate the activity of microglia, the resident macrophages of the central nervous system (CNS). A brief, non-intensive primary stimulus in the brain, such as a brief ischemic episode followed by reperfusion, may cause a neuroinflammatory response and some reversible changes in the redox environment, in such a manner that cells may return to homeostasis. It is a preconditioning tuning, which not only allows returning to homeostasis but also increases the resistance to further ischemic damage. On the other hand, a real pathological stimulus, such as protein aggregates, stroke, trauma, or the presence of DAMPs will cause a persistent neuroinflammatory response and a significant increase of oxidative stress, impairing the return to homeostasis. The persistence of the stimulus perpetuates the cell damage and induces even more oxidative stress, and both pathological events feed the neuroinflammatory response, forming a vicious cycle which ultimately leads to disease [9].

Following an electrical stimulation or by injecting adenosine triphosphate (ATP) locally, $\mathrm{Ca}^{2+}$ waves are elicited and spread out over hundreds of micrometers, as observed in acute brain slices [10]. This is an extraneuronal pathway for rapid long-distance signal transmission within the CNS. Following the application of glutamate in vitro, astrocytes undergo oscillatory elevation of cytoplasmic free calcium which propagates as waves within the cytoplasm of individual astrocytes and between adjacent astrocytes in confluent cultures [11]. Via stimulation of $G$ protein-coupled calcium sensing receptors, extracellular $\mathrm{Ca}^{2+}$ may amplify the inflammatory response activating the nucleotide-binding domain, leucine-rich-repeat-containing family, pyrin domain-containing 3 (NLRP3) inflammasome assembly, as shown in monocytes and macrophages [12]. The process occurs via the inositol/ $\mathrm{Ca}^{2+}$ pathway leading to the release of high levels of interleukin $1 \beta$ and other proinflammatory cytokines, such as IL- $1 \alpha$, IL- 6 and TNF. A kinetic curve of proinflammatory cytokines during amyloid betainduced oxidative stress in brain shows the same pattern of cytokines in function of time following the intracerebral amyloid beta injection [13].

A high metabolic rate of the brain (the brain consumes $49 \mathrm{ml}$ of oxygen in a minute, $20 \%$ of the total body $\mathrm{O}_{2}$ consumption [14], plus a low concentration of glutathione peroxidase (GPx) as occurs in neurodegenerative processes $[13,15]$ in addition to a high content of polyunsaturated fatty acids [16], these three factors make the brain particularly susceptible to oxidative damage [17].

There are several different phenomena leading to oxidative and/ or nitrosative stress in brain. The mitochondrial free radical leakage and the NADPH-oxidase activation are the main neurodegenerationrelated mechanisms, having the aging as a key intervening variable [18]. Under physiological conditions, up to $1 \%$ of the flow of electrons in the mitochondrial respiratory chain may lead to the formation of a dangerous by-product, superoxide anion $\left(\mathrm{O}_{2}^{-}\right)$[8]. However, the interference with energy metabolism, as occurs in neurodegenerative processes, dramatically increases the production of $\mathrm{O}_{2}^{-}$, [19]. Partially reduced species of molecular oxygen may attack iron/sulfur cores in a variety of enzymes. Even though $\mathrm{O}_{2}^{-}$is rapidly transformed into hydrogen peroxide $\left(\mathrm{H}_{2} \mathrm{O}_{2}\right)$ by the enzyme superoxide dismutase (SOD), $\mathrm{H}_{2} \mathrm{O}_{2}$ reacts with reduced transition metals (Fenton reaction) to produce the highly reactive hydroxyl radicals $(\mathrm{OH} \cdot)$. Additionally, $\mathrm{O}_{2}^{-}$reacts with nitric oxide (NO) to generate peroxynitrite anion (ONOO-) which in turn reacts with carbon dioxide causing damage to proteins through nitrotyrosine adducts and peroxidation of membrane lipids [20]. Either directly oxidized by reactive oxygen species (ROS), through the Fenton reaction or by addition to double bonds of DNA bases, or indirectly through alkylating agents, nucleic acids are also a sensitive target of oxidative stress [21].

An essential component of the redox control is the glutathione system that detoxifies reactive oxygen and nitrogen species as well as electrophiles produced by xenobiotics. By taking an electron from chemical species with an unpaired electron (free radical), the reduced glutathione (GSH) is completely oxidized to form GSSG by bonding two glutathionyl radicals. GSSG eventually may be reduced back to GSH by the action of the glutathione reductase enzyme and using $\mathrm{NADPH}$ reducing equivalents. The glutamate/cystine-antiporter system catalyzes the exchange of L-cystine for L-glutamate. Inside the cell, cystine transforms into cysteine, which provides thiol groups for replenishing the GSH system. The excitatory neurotransmitter glutamate, acting on its receptors, particularly N-methyl-D-aspartate (NMDA) receptors, activates channels that allow the influx of extracellular calcium. Thus, during neurodegenerative processes the overstimulation of ionotropic NMDA receptors leads to excessive calcium and sodium influx, precipitating membrane depolarization and the activation of voltage-dependent calcium channels. Glutamate activates also metabotropic receptors (mGluR), which couple to $G$ proteins. By modulating intracellular second messengers, such as the inositol-1,4,5-trisphosphate $\left(\mathrm{IP}_{3}\right), \mathrm{mGluR}$ induce neuroprotective pathways. However, they also increase cytosol calcium concentrations [22]. The massive entrance of $\mathrm{Ca}^{2+}$ activates a number of signaling pathways including calpains, proteases, protein kinases, nitric oxide synthase (NOS), calcineurin, calmodulin and endonucleases, in addition to the uncoupling of mitochondrial electron transfer from ATP synthesis. Interestingly, microglia metabolizes tryptophan via the kynurenine pathway, to produce kynurenic acid first and then quinolinic acid, both of them modulate NMDA receptors. Kynurenic acid antagonizes NMDA receptors, whereas quinolinic acid is a NMDAagonist. Proinflammatory cytokines favor quinolinic acid overproduction, which in turn activates NMDA receptors, leading to depression symptoms and excitotoxicity due to a glutamatergic effect [23]. Depression comes from the neurotransmitter serotonin depletion due to a deviation of the regular pathway tryptophan to 5-hydroxytryptamine (serotonin), the clinical translation of this phenomenon is known as "cytokine-induced sickness behavior" [24]. Additionally, quinolinic acid may directly increase synaptosomal glutamate release, as observed in vivo following the intra cerebroventricular quinolinic acid administration [25].

Glutamate also activates microglia and these cells, in addition to destructive free radicals, overproduce inflammatory cytokines such as interleukin 1- ${ }^{\beta}\left(\mathrm{IL}-1^{\beta}\right)$ and tumor necrosis factor (TNF), which in turn feedback the release of glutamate. Specifically, IL- $1^{\beta}$ stimulates glutamate uptake in glial cells by accelerating membrane trafficking of $\mathrm{Na}^{+} / \mathrm{K}^{+}$-ATPase via actin depolymerization [26], whereas TNF potentiates glutamate neurotoxicity by inhibiting glutamate uptake [27] or releases glutamate from hemi-channels of activated microglia in an autocrine manner [28]. Both IL-1 $\beta$ and TNF- $\alpha$ induce glutaminase expression, associated with an intracellular and extracellular increased concentrations of glutamate and with neuronal death via an apoptosislike mechanism, which selectively targets neurons expressing glutamate receptors [29-31]. Finally, the activation of the $\mathrm{Ca}^{2+}$ permeable NMDA receptor alters the mitochondrial potential, causing membrane depolarization, affecting the mitochondrial electron transport linked to cytochrome $\mathrm{c}$ releasing [32]. These alterations are associated with a significant leak of superoxide anion toward the cytosol. 
Thus, excitotoxicity and oxidative stress, as occurs with oxidative stress and inflammation, are closely related phenomena, so that these mechanisms feedback each other constantly, creating synergies. This brief summary of neuroinflammation and free radicals and their vicious relationship with glutamate along the neurodegenerative pathology, may aid to understand the possible role of cannabinoids in neurodegeneration.

\section{Endocannabinoids}

Anandamide (AEA) and 2-arachidonylethanolamide (2-AG) are the best-known endogenous cannabinoids. They are bioactive lipids acting on specific $G_{\text {iir }}$ protein-coupled cannabinoid receptors (CB1R and CB2R), widely distributed in the CNS in both neurons and glial cells [33-35].

The activation of $\mathrm{CB}$ receptors by endocannabinoids has a protective role in CNS homeostasis. For example, microglial cells synthesize the 2-AG ligand from phosphatidic acid, as well as CB1R and CB2R. 2-AG via a CB2R-dependent mechanism activates ERK1, and microglia proliferation [36], contributing to the proliferative response of microglial cells, as occurs in neurodegenerative disorders. In fact, $\mathrm{CB} 2 \mathrm{R}$ as well as its degrading enzyme fatty acid amide hydrolase (FAAH) are selectively over expressed in neuritic plaqueassociated glia in Alzheimer's disease (AD) brains [37]. In fact, the phyto cannabinoid cannabidiol (CBD) acts mostly stimulating the endogenous cannabinoid signaling by suppressing FAAH [38]. In acute neuroinflammation, following a traumatic brain injury (TBI), microglial over reactivity diminishes with minocycline, which also activates $\mathrm{CB} 1 \mathrm{R}$ and $\mathrm{CB} 2 \mathrm{R}$. However, microglial reactivity and the other TBI-derived pathological issues, such as brain edema, neurological impairment and diffuse axonal injury, are prevented with the administration of CB1R and CB2R antagonists [39]. It is worth to remember that $\mathrm{CB} 2 \mathrm{R}$ in microglia are not constitutive but inducible receptors, particularly under neuroinflammatory conditions [40]. Recently, microglia harvested from an AD mouse model brain, but lacking CB2R also, have been demonstrated to be less responsive to proinflammatory stimuli than the $\mathrm{CB}_{2} \mathrm{R}^{+/+}$mice [41]. Additionally, non$\mathrm{CB} 1 \mathrm{R} /$ non-CB2R G protein-coupled receptor (GPR) subtypes, such as GPR55, are new cannabinoid receptors that exert microglia-dependent neuroprotection after excitotoxic lesion. They act independently of intracellular $\mathrm{Ca}^{2+}$ and $\mathrm{p} 38$ or $\mathrm{p} 44 / \mathrm{p} 42$ MAPK phosphorylation [42] (Figure 1).

Endocannabinoids are produced in response to excitotoxic challenges and activate CB1R and CB2R, but also PPAR $\gamma$, a powerful metabolic regulator. By these means, endocannabinoids become neuroprotective against AMPA-induced excitotoxicity, as evaluated in a model of multiple sclerosis [43]. In the presence of quinolinic acid, a metabolite of the kynurenine pathway, analog of glutamate, into rat striatal culturedcells and rat brain synaptosomes, initiates an excitotoxic process as the above described. However, by adding agonists of cannabinoid receptors the excitotoxicity is prevented, as well as the associated mitochondrial dysfunction and oxidative stress [44].

Depolarization of a postsynaptic neuron, as occurs following a traumatic brain injury or by overstimulation of ionotropic NMDA receptors as occurs in neurodegenerative processes (see above), facilitates the release of endocannabinoids via $\mathrm{Ca}^{2+}$ influx [45]. Endocannabinoids may diffuse across the synaptic cleft toward inhibitory or excitatory presynaptic terminals containing CB1R, acting in this manner as retrograde messengers. Activated CB1R inhibit voltage-gated $\mathrm{Ca}^{2+}$ channels through the activation of heterotrimeric
G-proteins, which it results in release inhibition of glutamate, related to excitotoxicity. 2-arachidonylglycerol (2-AG), 2-arachidonyl glycerol ether (2-AGE), and anandamide (AEA), as well as the cannabimimetic amino alkylindole WIN, may initiate a voltage-dependent $\mathrm{N}$-type $\mathrm{Ca}^{2+}$ channel inhibition via $\mathrm{CB} 1 \mathrm{R}$, as demonstrated in dissociated superior cervical ganglion neurons [46]. Also, by inhibiting adenylyl cyclase, that outlasts direct action at the CB1R receptor, endocannabinoids may prevent cell death, being capable of reducing cytosolic free $\mathrm{Ca}^{2+}$ via a cAMP/PKA-dependent process during a neurotoxic event [47].

The pathogenic mechanisms in neurodegenerative disorders involve sodium, potassium, and calcium channels, as well as the glutamate receptors NMDA and AMPA. In this context, cannabinoids can also interact with ion channels through CB1R, but not through CB2R, by modulating voltage-dependent ion channels, decreasing calcium currents through both $\mathrm{N}$ - and $\mathrm{P} / \mathrm{Q}$ type voltage-sensitive $\mathrm{Ca}^{2+}$ channels $[48,49]$ and increasing G-protein-coupled inwardly rectifying $\mathrm{K}^{+}$channels [49] and A-type $\mathrm{K}^{+}$channels [50-52]. By all these means, cannabinoids could be implicated in the inhibition of neurotransmitter release at presynaptic level. The effect, carried out by a mechanism known as retrograde signaling (see above) may affect the release of neurotransmitters, such as acetylcholine, dopamine, GABA, histamine, serotonin, glutamate, cholecystokinin, D-aspartate, glycine, and noradrenaline $[50,53]$.

As outlined above, the majority of these effects are CB1R receptor dependent, although there is evidence to suggest that cannabinoids can modulate ion channel function directly. Physiological modulation of voltage-gated ion channels including $\mathrm{Ca}^{2+}$ channels, $\mathrm{Na}^{+}$channels, some types of $\mathrm{K}^{+}$channels, and ligand-gated ion channels such as serotonin type 3, nicotinic acetylcholine, and glycine receptors are observed at significant pharmacologic concentrations of endocannabinoids $[3,48,50,54]$. At the same time, it has also been demonstrated a modulatory effect of endocannabinoids on other ion-transporting membrane proteins such as gap junction channels, and the transporters for neurotransmitters and transient potential receptor-class (TRP) channels, related to influx of extracellular $\mathrm{Ca}^{2+}[1]$. Probably these direct actions of endocannabinoids are due to their lipophilic structures; however, the mechanisms are poorly understood.

Despite the role of endogenous cannabinoids against oxidative stress, neuroinflammation and excitotoxicity in brain, the use of phytocannabinoids reveals controversial results.

\section{Phytocannabinoids}

Cannabis is a "chemical factory", producing more than 500 different chemical compounds. Seventy of them are cannabinoids produced by the enzymatic condensation of terpens (geranyldiphosphate) and phenols, like olivetolic or divarinic acid. Thus, they are terpenophenols, classified into different categories: cannabigerols (CBG), cannabichromenes (CBC), cannabidiols (CBD), tetrahydro cannabinols (THC), cannabinol (CBN),cannabinodiol (CBDL) and other cannabinoids such as cannabicyclol (CBL), cannabielsoin (CBE), cannabitriol (CBT).

Except THC and CBD, there are few reports about a role for the other phytocannabinoids on neurodegenerative processes. For example, a cannabigerol quinone may alleviate neuroinflammation, decreasing microglia reactivity and modulating the expression of genes involved in the neuroinflammatory pathophysiology, as observed in a chronic model of multiple sclerosis [55].

Cannabinol may have a role in microglial cell migration. Microglial 
cells express both CB1R and CB2R. Some CB2R are expressed at the leading edges of microglial motile protrusions and may be involved in recruiting microglial cells toward dying neurons. Such a cell migration is triggered by chemo attractants acting on transmembrane/Gi/o-coupled receptors as occurs with THC, which is involved in the migration of macrophages [56]. The same occurs by using endocannabinoids, such as the glutamate-induced 2-AG. However CBN the same as CBD may antagonize the 2-AG-induced recruitment of microglial cells [57] reducing the neuroinflammation promoted by glutamate.

THC and CBD have been widely explored in neuroinflammation, excitotoxicity and oxidative stress, which are key pathogenic events in neurodegeneration.

The non-psychoactive CBD reportedly reduces the over-reactivity in microglial cells. Apart from reducing microglial recruitment, as seen above, CBD also decreases the transmigration of blood leukocytes by downregulating the expression of vascular cell adhesion molecule-1 (VCAM-1), chemokines (CCL2 and CCL5) and the proinflammatory cytokine IL-1 $\beta$, as observed in a viral model of multiple sclerosis [58]. Also, CBD may increase significantly microglial phagocytosis in a $\mathrm{Ca}^{2+}$-dependent manner and mediatedby PI3K signaling, via transient receptor potential (TRP) channel activation [59]. In PC12 neurons stimulated with amyloid-beta, the major constituent of senile plaques observed in $\mathrm{AD}$ brains, $\mathrm{CBD}$ also have demonstrated an antioxidant effect by inhibiting inducible nitric oxide synthase protein expression and nitric oxide production which is achieved, in a dose-dependent manner, by blocking phosphorylated form of p38 MAP kinase and the transcription factor nuclear factor- $\kappa \mathrm{B}$ activation [60]. Both antioxidant and anti-inflammatory effects appear in a mouse model of $\mathrm{AD}$ inoculated with human $\mathrm{A} \beta$ following the administration of CBD [61].

Additionally, CBD may have a role on excitotoxicity as well. This phenomenon, measured by the glutamate/ $\mathrm{N}$-acetylaspartate ratio, can be prevented by using CBD, as demonstrated in vivo in a model of hypoxic-ischemic brain injury in newborn. Oxidative stress and inflammation parameters may also significantly decrease in that model when using CBD. The neuroprotective effect implicates CB2R and 5-hydroxytryptamine [5HT(1A)] receptors [62].

Despite all the above, CBD could have a deleterious effect on cell functioning. Inhibition of microglia by CBD can be suppressive, as demonstrated in murine primary microglial cultures treated with CBD. The result is induction of apoptosis in a timeand concentrationdependent manner [63]. In order to regulate intracellular $\mathrm{Ca}^{2+}$ levels, CBD may also target mitochondria. Nonetheless, it is a bidirectional regulation, depending on the excitability of cells. Under a physiological $\mathrm{K}^{+} / \mathrm{Ca}^{2+}$ level, CBD may cause a subtle rise in free cytosolic $\mathrm{Ca}^{2+}$; however, under high-excitability conditions a reduction of free cytosolic $\mathrm{Ca}^{2+}$ is observed once CBD is applied. Even CBD may prevent $\mathrm{Ca}^{2+}$ oscillations under high-excitability conditions [64] (Figure 1).

THC reduces lipopolysaccharide-induced mRNAs of proinflammatory cytokines, such as IL- $1 \alpha$, IL- $1 \beta$, IL- 6 , and TNF- $\alpha$, as observed in cortical microglial cells from neonatal rat [65]. The effect seems to be not mediated by CB1R or CB2R. However, the most noticeable effect of THC on neurodegenerative pathways is preventing excitotoxicity [66]. Via a CB1R-receptor-mediated mechanism, THC may reduce the volume of cytotoxic edema and reduces neuronal damage induced by excitotoxicity. Such a neuroprotective effect may be inhibited by using a CB1R antagonist. During the acute and late phase after induction of excitotoxicity THC may also inhibit astrogliosis, but this is a non-CB1R-receptor-controlled mechanism [67].

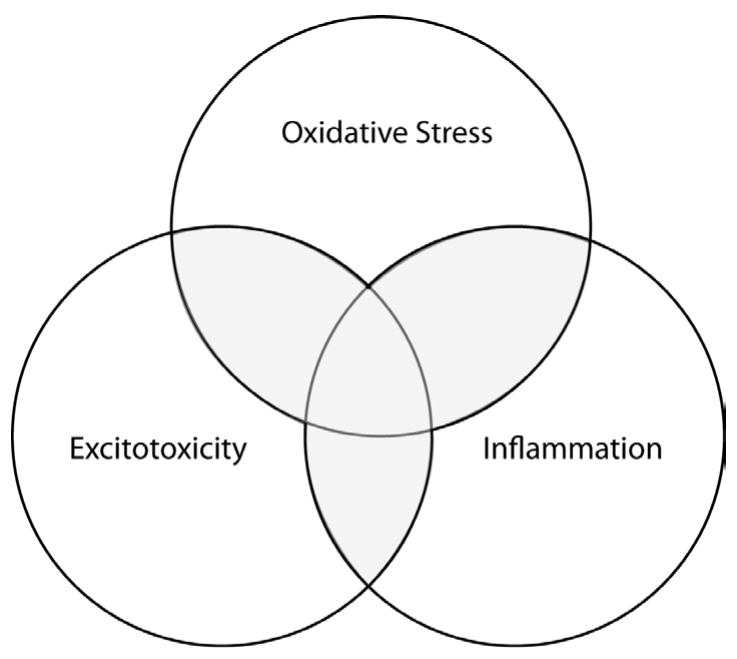

Figure 1: Main pathogenic mechanisms behind neurodegeneration. The grey area corresponds to a feedback and synergy zone. The homeostatic activity of endocannabinoids and their receptors is defined within this zone. The alleged neuroprotective activity of phytocannabinoids, such as $\mathrm{CBD}$ and $\mathrm{THC}$ or its combination, should find the right dose to produce the desired effect. The type and state of activity of their receptors as well as the level of cell damage are factors worth to consider.(the original illustration is attached in .tiff and eps format).

$\mathrm{CB} 1 \mathrm{R}$ receptor reduces excitotoxicity by inhibiting $\mathrm{Ca}^{2+}$ influx through voltage-gated $\mathrm{Ca}^{2+}$ channels [48]. Additionally, THC acting on CB1R may also inhibit cAMP formation and this affects signaling events through the cAMP pathway distal to adenylatecyclase, leading to a decrease in forskolin-inducible protein kinase A (PKA) activity [68]. In addition, downstream the cAMP cascade THC may inhibit the transcriptionfactor NF- $\mathrm{BB}$ and, by this mean, THC attenuates the inducible nitric oxide synthase (iNOS) gene expression, as demonstrated in LPS-activated macrophages [69]. By inhibiting NOS and PKA cannabinoids may protect neurons from excitotoxic injury, as demonstrated when NMDA-induced neuronal cell death and NO production were evaluated in cell cultures as well as in vivo using both wild-type and CB1R-knockout mice [70].

Acting on CB1R, THC also exerts a close regulation of Akt and GSK-3 phosphorylation in brain, being the Akt/GSK-3 modulation a THC dose-dependent event, which it follows to the activation of PI3K, but does not involves the MAPK/ERK signaling pathway, as observed in vivo in the hippocampus of mice brains [70]. The PI3K/Akt/GSK-3 pathway is widely known to be involved in survival neuron signaling, and its inhibition leads to excitotoxicity and neurodegeneration $[18,71]$.

\section{The Opposite Effect}

THC may induce a transient, modest increase in $\mathrm{Ca}^{2+}$ in cultured neuronal cells in a process involving phospholipase $\mathrm{C}$ and via a CB1R-receptor-mediated mechanism [79]. It has a low efficacy on the stimulation of the CB2R-receptor, indeed. This holds in the acute phase as well as the late phase, after inducing excitotoxicity and testing THC at a micromolar range.

THC may also induce the activation of the stress-activated protein kinase, c-Jun $\mathrm{N}$-terminal kinase (JNK) via the $\mathrm{CB} 1 \mathrm{R}$ receptor. In this manner THC promotes cytochrome $c$ release and activates the caspase-3 cell death pathway resulting in DNA fragmentation and programmed cell death, as observed in rat cultured cortical neurons 
$[80,81]$. It is worth to mention that THC was employed also in the micromolar range in these experiments.

It is well-known the psychoactive effects of THC. By injecting THC in Nrg1 HET mice, an animal model of schizophrenia, the expression of the NMDA receptor in the hippocampus is increased, which is not observed in THC-treated wild type mice. Overexpression of NMDA receptors induce differential expression of proteins involved in NMDA receptor trafficking to the synaptic membrane, as well as lipid raft stabilization of synaptic NMDA receptors, and homeostatic responses to dampen excitotoxicity [82]. In addition, by interfering in cAMP formation, as mentioned above, THC may also inhibit synaptic function. In fact, chronic administration of THC impairs spatial memory and reduces a learning-related transcription factor (zif268) expression in the mouse forebrain [83]. This is consistent with the significant reduction in the number of synapses per unit volume $(44 \%)$ as well as a reduction in the dendritic length of CA3 pyramidal neurons, as observed in rats receiving high doses of THC (10 to $60 \mathrm{mg} /$ $\mathrm{kg}$ ), during a long period of treatment (90 days) [84].

Applied in vitro upon oligodendrocyte cultures CBD induces a mitochondrial $\mathrm{Ca}^{2+}$ which is related to a membrane potential disruption, critical in mitochondrial viability, and subsequently an intracellular $\mathrm{Ca}^{2+}$ and $\mathrm{ROS}$ rise, reducing oligodendroglial viability [85]. Indeed, in vitro experiments using BV-2 microglial cells have demonstrated that $\mathrm{CBD}$ colocalizes with voltage-dependent anion channel (VDAC)-rich mitochondrial membranes, by this mean CBD induces mitochondrial swelling, loss of mitochondrial membrane potential with increased ROS production and, eventually, dose-dependently cell death after $2 \mathrm{~h}$ treatment, under serum-free conditions [86]. Interestingly, these lethal effects appear by adding CBD in the order of 5 to $10 \mu \mathrm{M}$, even for 2 hours. The opposite, neuroprotective effects against the uncoupler carbonyl cyanide-p-trifluoromethoxyphenylhydrazone (FCCP), or against hydrogen peroxide were observed in vitro by using a significantly lower dose of CBD $(1 \mu \mathrm{M})$ [64] (Table 1).

\section{Conclusions}

Research on cannabinoids has been growing exponentially in the last few years. Searching for "cannabinoids" in PubMed, between the years 2010 and January 2015, results in 1827 publications, which is $140 \%$ of the published papers in thirty years, between 1970 and 2000 .

There is a growing body of evidence about the role of CBD and THC, or the combination of both acting on key features of neurodegeneration, such as inflammation, oxidative stress and excitotoxicity. Thus, cannabinoids have been proposed for the treatment of Alzheimer Disease [87], Parkinson [88], multiple sclerosis [89], amyotrophic

\begin{tabular}{|c|c|c|c|c|}
\hline \multirow{2}{*}{ Cannabinoid } & \multirow{2}{*}{ Target receptors } & \multirow{2}{*}{$\begin{array}{c}\text { Best known mechanisms } \\
\text { of action }\end{array}$} & \multirow{2}{*}{$\begin{array}{c}\text { Effects in } \\
\text { Neurodegeneration }\end{array}$} & \multirow{2}{*}{ Ref. } \\
\hline & & & & \\
\hline Delta-9 & $\begin{array}{l}\text { CB1R. Less active } \\
\text { with CB2R. Even it } \\
\text { may antagonize } \\
\text { CB2R (72). } \\
\text { PPARs agonist (73). } \\
\text { 5-HT(1A) antagonist } \\
\text { (74). }\end{array}$ & $\begin{array}{l}\text { Acting on G protein- } \\
\text { coupled receptors THC } \\
\text { regulates second } \\
\text { messenger systems. It } \\
\text { affects potassium and } \\
\text { calcium ion channels as } \\
\text { well as cyclical AMP. }\end{array}$ & $\begin{array}{l}\text { It affects microglial } \\
\text { migration; possesses anti- } \\
\text { inflammatory and } \\
\text { antiexcitotoxic effects; } \\
\text { reduces edema, astrogliosis } \\
\text { and it is antioxidant. }\end{array}$ & $\begin{array}{l}(56, \\
65- \\
69)\end{array}$ \\
\hline Cannabidiol & $\begin{array}{l}\text { It binds to TPRV1, } \\
\text { activates 5-HT1A (at } \\
\text { high concentration } \\
\text { levels), antagonizes } \\
\text { GPR55 (75), and it is } \\
\text { a PPARs agonist } \\
\text { (76). } \\
\text { It binds less actively } \\
\text { to CB2R and CB1R } \\
\text { (77). }\end{array}$ & $\begin{array}{l}\text { It suppresses the } \\
\text { endocannabinoid degrader } \\
\text { FAAH (38), enhancing } \\
\text { endocannabinoid } \\
\text { responses. It controls } \\
\text { vascular tone, immune cell } \\
\text { function and cell } \\
\text { migration. } \\
\text { Acting on PPARs, CBD } \\
\text { reduces the inflammatory } \\
\text { cascade and may promote } \\
\text { neurogenesis (60, 61, 78). }\end{array}$ & $\begin{array}{l}\text { CBD reduces the over- } \\
\text { reactivity in microglial } \\
\text { cells, reduces the microglial } \\
\text { recruitment, but increases } \\
\text { the microglial phagocytosis } \\
\text { diminishes VCAM-1 and } \\
\text { chemokines expression. It } \\
\text { is a potent antioxidant and } \\
\text { inhibits the NF- } 囚 \mathrm{~B} \\
\text { expression. Antagonizes the } \\
\text { effect of 2-AG. }\end{array}$ & $\begin{array}{l}(28, \\
57- \\
60)\end{array}$ \\
\hline
\end{tabular}

Table 1: The effects of THC and CBD on key neurodegenerative mechanisms. 
lateral sclerosis [90], stroke [91], Huntington's disease (HD) and basal ganglia disorders in general [92], or traumatic brain injury [93].

However, evidence of proinflammatory, excitotoxic, even proapoptotic effects induced by cannabinoids are worth to consider, particularly when pretending to employ them as therapeutics in neurodegenerative diseases. "The rule of thumb" that cannabinoids typically exhibit nanomolar affinities at CB1R and CB2R, in such a manner that testing them at concentrations two orders of magnitude above their affinity will produce off-target effects [94], it might find some other factors to consider, such as dose, treatment lasting, type of cells and state of activity or pathological condition (Figure 1). It is worth evaluating in multiple experiments the THC: CBD ratio when used in combination, in order to avoid not only the psychoactive effects, but also the unexpected antagonic effects once cannabinoids find their receptors.

It would be unwise to draw major conclusions and defining to cannabinoids as neuroprotective or neurotoxic substances if conditions related to contradictory reports remain confusing.

\section{References}

1. Oz M (2006) Receptor-independent actions of cannabinoids on cell membranes: focus on endocannabinoids. Pharmacol Ther 111: 114-144.

2. Alexander SP, Kendall DA (2007) The complications of promiscuity: endocannabinoid action and metabolism. Br J Pharmacol 152: 602-623.

3. Campillo NE, Páez JA (2009) Cannabinoid system in neurodegeneration: new perspectives in Alzheimer's disease. Mini Rev Med Chem 9: 539-559.

4. Hall W, Solowij N (1998) Adverse effects of cannabis. Lancet 352: 1611-1616.

5. Moghadami-Tabrizi N, Daftari H, Behjatnia $\mathrm{Y}$, Dabirashrafi $\mathrm{H}$, Zandinejad K (1996) Complication of Laparoscopic Coagulation of an Endometrioma Surface. J Am Assoc Gynecol Laparosc 3: S31.

6. Molina-Holgado F, Rubio-Araiz A, Garcia-Ovejero D, Williams RJ, Moore JD, et al. (2007) CB2 cannabinoid receptors promote mouse neural stem cell proliferation. Eur J Neurosci 25: 629-634.

7. Morales-Garcia JA, Luna-Medina R, Alfaro-Cervello C, Cortes-Canteli M, Santos A, et al. (2011) Peroxisome proliferator-activated receptor gamma ligands regulate neural stem cell proliferation and differentiation in vitro and in vivo. Glia 59: 293-307.

8. Parri HR, Gould TM, Crunelli V (2001) Spontaneous astrocytic Ca2+ oscillations in situ drive NMDAR-mediated neuronal excitation. Nat Neurosci 4: 803-812.

9. Rosales-Corral S, Reiter RJ, Tan DX, Ortiz GG, Lopez-Armas G (2010) Functional aspects of redox control during neuroinflammation. Antioxid Redox Signal 13: 193-247

10. Schipke CG, Boucsein C, Ohlemeyer C, Kirchhoff F, Kettenmann H (2002) Astrocyte $\mathrm{Ca} 2+$ waves trigger responses in microglial cells in brain slices. FASEB J 16: 255-257.

11. Cornell-Bell AH, Finkbeiner SM, Cooper MS, Smith SJ (1990) Glutamate induces calcium waves in cultured astrocytes: long-range glial signaling. Science 247: 470-473.

12. Rossol M, Pierer M, Raulien N, Quandt D, Meusch U, et al. (2012) Extracellular $\mathrm{Ca} 2+$ is a danger signal activating the NLRP3 inflammasome through G protein-coupled calcium sensing receptors. Nat Commun 3: 1329.

13. Rosales-Corral S, Tan DX, Reiter RJ, Valdivia-Velazquez M, Acosta-Martinez JP, et al. (2004) Kinetics of the neuroinflammation-oxidative stress correlation in rat brain following the injection of fibrillar amyloid-beta onto the hippocampus in vivo. J Neuroimmunol 150: 20-28.

14. Kennedy C, Sokoloff $L$ (1957) An adaptation of the nitrous oxide method to the study of the cerebral circulation in children; normal values for cerebral blood flow and cerebral metabolic rate in childhood. J Clin Invest 36: 1130-1137.

15. Mytilineou C, Kramer BC, Yabut JA (2002) Glutathione depletion and oxidative stress. Parkinsonism Relat Disord 8: 385-387.
16. Söderberg M, Edlund C, Kristensson K, Dallner G (1991) Fatty acid composition of brain phospholipids in aging and in Alzheimer's disease. Lipids 26: 421-425

17. Miranda S, Opazo C, Larrondo LF, Munoz FJ, Ruiz F, et al. (2000) The role of oxidative stress in the toxicity induced by amyloid beta-peptide in Alzheimer's disease. Prog Neurobiol 62: 633-648.

18. Rosales-Corral SA, Acuna-Castroviejo D, Coto-Montes A, Boga JA Manchester LC, et al. (2012) Alzheimer's disease: pathological mechanisms and the beneficial role of melatonin. J Pineal Res 52: 167-202.

19. Gandhi S, Abramov AY (2012) Mechanism of oxidative stress in neurodegeneration. Oxid Med Cell Longev 2012: 428010.

20. Rosales-Corral S, Reiter RJ, Tan DX, Ortiz GG, Lopez-Armas G (2010) Functional aspects of redox control during neuroinflammation. Antioxid Redox Signal 13: 193-247.

21. Zong WX, Ditsworth D, Bauer DE, Wang ZQ, Thompson CB (2004) Alkylating DNA damage stimulates a regulated form of necrotic cell death. Genes Dev 18: $1272-1282$.

22. Fagni L, Chavis $P$, Ango F, Bockaert J (2000) Complex interactions between mGluRs, intracellular $\mathrm{Ca} 2+$ stores and ion channels in neurons. Trends Neurosci 23: 80-88.

23. Steiner J, Walter M, Gos T, Guillemin GJ, Bernstein HG, et al. (2011) Severe depression is associated with increased microglial quinolinic acid in subregions of the anterior cingulate gyrus: evidence for an immune-modulated glutamatergic neurotransmission? J Neuroinflammation 8: 94.

24. Hilmas C, Pereira EF, Alkondon M, Rassoulpour A, Schwarcz R, et al. (2001) The brain metabolite kynurenic acid inhibits alpha7 nicotinic receptor activity and increases non-alpha7 nicotinic receptor expression: physiopathological implications. J Neurosci 21: 7463-7473.

25. Tavares RG, Schmidt AP, Abud J, Tasca Cl, Souza DO (2005) In vivo quinolinic acid increases synaptosomal glutamate release in rats: reversal by guanosine. Neurochem Res 30: 439-444.

26. Namekata K, Harada C, Kohyama K, Matsumoto Y, Harada T (2008) Interleukin-1 stimulates glutamate uptake in glial cells by accelerating membrane trafficking of $\mathrm{Na}+/ \mathrm{K}+-\mathrm{ATP}$ ase via actin depolymerization. Mol Cel Biol 28: 3273-3280.

27. Zou JY, Crews FT (2005) TNF alpha potentiates glutamate neurotoxicity by inhibiting glutamate uptake in organotypic brain slice cultures: neuroprotection by NF kappa B inhibition. Brain Res 1034: 11-24.

28. Takeuchi H, Jin S, Wang J, Zhang G, Kawanokuchi J, et al. (2006) Tumor necrosis factor-alpha induces neurotoxicity via glutamate release from hemichannels of activated microglia in an autocrine manner. J Biol Chem 281: 21362-21368.

29. Chaparro-Huerta V, Rivera-Cervantes MC, Torres-Mendoza BM, BeasZarate C (2002) Neuronal death and tumor necrosis factor-alpha response to glutamate-induced excitotoxicity in the cerebral cortex of neonatal rats. Neurosci Lett 333: 95-98.

30. Ankarcrona M, Dypbukt JM, Bonfoco E, Zhivotovsky B, Orrenius S, et al. (1995) Glutamate-induced neuronal death: a succession of necrosis or apoptosis depending on mitochondrial function. Neuron 15: 961-973.

31. Ye L, Huang Y, Zhao L, Li Y, Sun L, et al. (2013) IL-1beta and TNF-alpha induce neurotoxicity through glutamate production: a potential role for neuronal glutaminase. J Neurochem 125: 897-908.

32. Luetjens CM, Bui NT, Sengpiel B, Munstermann G, Poppe M, et al. (2000) Delayed mitochondrial dysfunction in excitotoxic neuron death: cytochrome $c$ release and a secondary increase in superoxide production. J Neurosci 20 : 5715-5723.

33. Onaivi ES (2006) Neuropsychobiological evidence for the functional presence and expression of cannabinoid CB2 receptors in the brain. Neuropsychobiology 54: $231-246$.

34. Nunez E, Benito C, Pazos MR, Barbachano A, Fajardo O, et al. (2004) Cannabinoid CB2 receptors are expressed by perivascular microglial cells in the human brain: an immunohistochemical study. Synapse 53: 208-213.

35. Glass M, Dragunow M, Faull RL (1997) Cannabinoid receptors in the human brain: a detailed anatomical and quantitative autoradiographic study in the fetal, neonatal and adult human brain. Neuroscience 77: 299-318.

36. Carrier EJ, Kearn CS, Barkmeier AJ, Breese NM, Yang W, et al. (2004) Cultured 
rat microglial cells synthesize the endocannabinoid 2-arachidonylglycerol, which increases proliferation via a CB2 receptor-dependent mechanism. Mo Pharmacol 65: 999-1007.

37. Benito C, Nunez E, Tolon RM, Carrier EJ, Rabano A, et al. (2003) Cannabinoid CB2 receptors and fatty acid amide hydrolase are selectively overexpressed in neuritic plaque-associated glia in Alzheimer's disease brains. J Neurosci 23: 11136-11141.

38. De Petrocellis L, Ligresti A, Moriello AS, Allarà M, Bisogno T, et al. (2011) Effects of cannabinoids and cannabinoid-enriched Cannabis extracts on TRP channels and endocannabinoid metabolic enzymes. Br J Pharmacol 163 1479-1494.

39. Lopez-Rodriguez AB, Siopi E, Finn DP, Marchand-Leroux C, Garcia-Segura LM, et al. (2015) CB1 and CB2 Cannabinoid Receptor Antagonists Prevent Minocycline-Induced Neuroprotection Following Traumatic Brain Injury in Mice. Cereb Cortex 25: 35-45.

40. Maresz K, Carrier EJ, Ponomarev ED, Hillard CJ, Dittel BN (2005) Modulation of the cannabinoid CB2 receptor in microglial cells in response to inflammatory stimuli. J Neurochem 95: 437-445.

41. Schmole AC, Lundt R, Ternes S, Albayram O, Ulas T, et al. (2014) Cannabinoid receptor 2 deficiency results in reduced neuroinflammation in an Alzheimer's disease mouse model. Neurobiol Aging 36:710-719.

42. Kallendrusch S, Kremzow S, Nowicki M, Grabiec U, Winkelmann R, et al. (2013) The $G$ protein-coupled receptor 55 ligand I-alpha-lysophosphatidylinositol exerts microglia-dependent neuroprotection after excitotoxic lesion. Glia 61 , 1822-1831 THC/CBD in Neurodegeneration 15

43. Loría F, Petrosino S, Hernangómez M, Mestre L, Spagnolo A, et al. (2010) An endocannabinoid tone limits excitotoxicity in vitro and in a model of multiple sclerosis. Neurobiol Dis 37: 166-176.

44. Rangel-Lopez E, Colin-Gonzalez AL, Paz-Loyola AL, Pinzon E, Torres I, et al. (2014) Cannabinoid receptor agonists reduce the short-term mitochondria dysfunction and oxidative stress linked to excitotoxicity in the rat brain. Neuroscience 285C: 97-106.

45. Ohno-Shosaku T, Hashimotodani Y, Ano M, Takeda S, Tsubokawa H, et al (2007) Endocannabinoid signalling triggered by NMDA receptor-mediated calcium entry into rat hippocampal neurons. J Physiol 584: 407-418.

46. Guo J, and Ikeda SR (2004) Endocannabinoids modulate N-type calcium channels and G-protein-coupled inwardly rectifying potassium channels via CB1 cannabinoid receptors heterologously expressed in mammalian neurons. Mol Pharmacol 65: 665-674.

47. Zhuang SY, Bridges D, Grigorenko E, McCloud S, Boon A, et al. (2005) Cannabinoids produce neuroprotection by reducing intracellular calcium release from ryanodine-sensitive stores. Neuropharmacology 48: 1086-1096.

48. Mackie K, Hille B (1992) Cannabinoids inhibit N-type calcium channels in neuroblastoma-glioma cells. Proc Natl Acad Sci U S A 89: 3825-3829.

49. Mackie K, Lai Y, Westenbroek R, Mitchell R (1995) Cannabinoids activate an inwardly rectifying potassium conductance and inhibit Q-type calcium currents in AtT20 cells transfected with rat brain cannabinoid receptor. J Neurosci 15 : 6552-6561.

50. Croxford JL (2003) Therapeutic potential of cannabinoids in CNS disease. CNS Drugs 17: 179-202.

51. Demuth DG, Molleman A (2006) Cannabinoid signalling. Life Sci 78: 549-563.

52. Centonze D, Finazzi-Agrò A, Bernardi G, Maccarrone M (2007) The endocannabinoid system in targeting inflammatory neurodegenerative diseases. Trends Pharmacol Sci 28: 180-187.

53. Wilson RI, Nicoll RA (2001) Endogenous cannabinoids mediate retrograde signalling at hippocampal synapses. Nature 410: 588-592.

54. Tanveer R, McGuinness N, Daniel S, Gowran A,Campbell VA (2012) Cannabinoid receptors and neurodegenerative diseases. Wiley Interdisciplinary Reviews: Membrane Transport and Signaling 1: 633-639.

55. Amigo J, Phillips C, Lareu M, Carracedo A (2008) The SNPforID browser: an online tool for query and display of frequency data from the SNPforID project. Int J Legal Med 122: 435-440.

56. Schwartzfarb L, Needle M, Chavez-Chase M (1974) Dose-related inhibition of leukocyte migration by marihuana and delta-9-tetrahydrocannabinol (THC) in vitro. J Clin Pharmacol 14: 35-41.
57. Walter L, Franklin A, Witting A, Wade C, Xie Y, et al. (2003) Nonpsychotropic cannabinoid receptors regulate microglial cell migration. J Neurosci 23 1398-1405.

58. Mecha M, Feliu A, Inigo PM, Mestre L, Carrillo-Salinas FJ, et al. (2013) Cannabidiol provides long-lasting protection against the deleterious effects of inflammation in a viral model of multiple sclerosis: a role for A2A receptors. Neurobiol Dis 59: 141-150.

59. Hassan S, Eldeeb K, Millns PJ, Bennett AJ, Alexander SP, et al. (2014) Cannabidiol enhances microglial phagocytosis via transient receptor potentia (TRP) channel activation. Br J Pharmacol 171: 2426-2439.

60. Esposito G, De Filippis D, Maiuri MC, De Stefano D, Carnuccio R, et al. (2006) Cannabidiol inhibits inducible nitric oxide synthase protein expression and nitric oxide production in beta-amyloid stimulated PC12 neurons through p38 MAP kinase and NF-kappaB involvement. Neurosci Lett 399: 91-95.

61. Esposito G, De Filippis D, Maiuri MC, De Stefano D, Carnuccio R, et al. (2006) Cannabidiol inhibits inducible nitric oxide synthase protein expression and nitric oxide production in beta-amyloid stimulated PC12 neurons through p38 MAP kinase and NF-kappaB involvement. Neurosci Lett 399: 91-95.

62. Esposito G, Scuderi C, Savani C, Steardo L Jr, De Filippis D, et al. (2007) Cannabidiol in vivo blunts beta-amyloid induced neuroinflammation by suppressing IL-1beta and iNOS expression. Br J Pharmacol 151: 1272-1279.

63. Pazos MR, Mohammed N, Lafuente H, Santos M, Martinez-Pinilla E, et al. (2013) Mechanisms of cannabidiol neuroprotection in hypoxic-ischemic newborn pigs: role of $5 \mathrm{HT}(1 \mathrm{~A})$ and $\mathrm{CB} 2$ receptors. Neuropharmacology 71 : 282-291.

64. Wu HY, Goble K, Mecha M, Wang CC, Huang CH, et al. (2012) Cannabidiolinduced apoptosis in murine microglial cells through lipid raft. Glia 60 1182-1190.

65. Ryan D, Drysdale AJ, Lafourcade C, Pertwee RG, Platt B (2009) Cannabidio targets mitochondria to regulate intracellular Ca2+ levels. J Neurosci 29: 20532063

66. Puffenbarger RA, Boothe AC, Cabral GA (2000) Cannabinoids inhibit LPS inducible cytokine mRNA expression in rat microglial cells. Glia 29: 58-69.

67. Gilbert GL, Kim HJ, Waataja JJ, Thayer SA (2007) Delta9-tetrahydrocannabino protects hippocampal neurons from excitotoxicity. Brain Res 1128: 61-69.

68. van der Stelt M, Veldhuis WB, Bär PR, Veldink GA, Vliegenthart JF, et al. (2001) Neuroprotection by Delta9-tetrahydrocannabinol, the main active compound in marijuana, against ouabain-induced in vivo excitotoxicity. J Neurosci 21 : 6475-6479.

69. Koh WS, Crawford RB,Kaminski NE (1997) Inhibition of protein kinase A and cyclic AMP response element (CRE)-specific transcription factor binding by delta9-tetrahydrocannabinol (delta9-THC): a putative mechanism of cannabinoid-induced immune modulation. Biochem Pharmacol 53: 1477-1484.

70. Jeon YJ, Yang KH, Pulaski JT, Kaminski NE (1996) Attenuation of inducible nitric oxide synthase gene expression by delta 9-tetrahydrocannabinol is mediated through the inhibition of nuclear factor- kappa B/Rel activation. Mol Pharmacol 50: 334-341.

71. Kim SH, Won SJ, Mao XO, Jin K, Greenberg DA (2006) Molecular mechanisms of cannabinoid protection from neuronal excitotoxicity. Mol Pharmacol 69: 691-696.

72. Molz S, Dal-Cim T, Budni J, Martin-de-Saavedra MD, Egea J, Romero A, et al.(2011) Neuroprotective effect of guanosine against glutamate-induced cell death in rat hippocampal slices is mediated by the phosphatidylinositol-3 kinase/Akt/ glycogen synthase kinase 3beta pathway activation and inducible nitric oxide synthase inhibition. J Neurosci Res 89: 1400-1408

73. Bayewitch M, Rhee MH, Avidor-Reiss T, Breuer A, Mechoulam R, et al. (1996) (-)-Delta9-tetrahydrocannabinol antagonizes the peripheral cannabinoid receptor-mediated inhibition of adenylyl cyclase. J Biol Chem 271: 9902-9905.

74. O'Sullivan SE (2007) Cannabinoids go nuclear: evidence for activation of peroxisome proliferator-activated receptors. Br J Pharmacol 152: 576-582.

75. Malone DT, Taylor DA (2001) Involvement of somatodendritic 5-HT(1A) receptors in Delta(9)-tetrahydrocannabinol-induced hypothermia in the rat. Pharmacol Biochem Behav 69: 595-601.

76. Ryberg E, Larsson N, Sjögren S, Hjorth S, Hermansson NO, et al. (2007) The orphan receptor GPR55 is a novel cannabinoid receptor. Br J Pharmacol 152 1092-1101. 
Citation: Rosales-Corral S, Hernández L, Gallegos M (2015) Cannabinoids in Neuroinflammation, Oxidative Stress and Neuro Excitotoxicity. Pharm Anal Acta 6: 346. doi:10.4172/2153-2435.1000346

Page 8 of 8

77. Juknat A, Rimmerman N, Levy R, Vogel Z, Kozela E (2012) Cannabidiol affects the expression of genes involved in zinc homeostasis in BV-2 microglial cells. Neurochem Int 61: 923-930.

78. Pertwee RG, Howlett AC, Abood ME, Alexander SP, Di Marzo V, et al. (2010) THC/CBD in Neurodegeneration 17

79. Pertwee RG, Howlett AC, Abood ME, Alexander SP, Di Marzo V, et al. (2010) International Union of Basic and Clinical Pharmacology. LXXIX. Cannabinoid receptors and their ligands: beyond CBâ, and CBâ. Pharmacol Rev 62: 588-631.

80. Esposito G, Scuderi C, Valenza M, Togna GI, Latina V, et al. (2011) Cannabidio reduces Abeta-induced neuroinflammation and promotes hippocampal neurogenesis through PPARgamma involvement. PLoS One 6: e28668.

81. Sugiura T, Kodaka T, Kondo $S$, Nakane $S$, Kondo $H$, et al. (1997) Is the cannabinoid CB1 receptor a 2-arachidonoylglycerol receptor? Structural requirements for triggering a Ca2+ transient in NG108-15 cells. J Biochem 122: 890-895

82. Downer E, Boland B, Fogarty M, Campbell V (2001) Delta 9-tetrahydrocannabinol induces the apoptotic pathway in cultured cortical neurones via activation of the CB1 receptor. Neuroreport 12: 3973-3978.

83. Downer EJ, Fogarty MP, Campbell VA (2003) Tetrahydrocannabinol-induced neurotoxicity depends on $\mathrm{CB} 1$ receptor-mediated $\mathrm{C}$-Jun $\mathrm{N}$-terminal kinase activation in cultured cortical neurons. Br J Pharmacol 140: 547-557.

84. Spencer JR, Darbyshire KM, Boucher AA, Kashem MA, Long LE, et al. (2013) Novel molecular changes induced by Nrg1 hypomorphism and Nrg1cannabinoid interaction in adolescence: a hippocampal proteomic study in mice. Frontiers in cellular neuroscience $7: 15$.

85. Boucher AA, Vivier L, Metna-Laurent M, Brayda-Bruno L, Mons Net al. (2009) Chronic treatment with Delta(9)-tetrahydrocannabinol impairs spatial memory and reduces zif268 expression in the mouse forebrain. Behav Pharmacol 20: $45-55$

86. Scallet AC, Uemura E, Andrews A, Ali SF, McMillan DE, et al. (1987) Morphometric studies of the rat hippocampus following chronic delta-9tetrahydrocannabinol (THC). Brain Res 436: 193-198.
87. Mato S, Victoria Sánchez-Gómez M, Matute C (2010) Cannabidiol induces intracellular calcium elevation and cytotoxicity in oligodendrocytes. Glia 58 1739-1747.

88. Rimmerman N, Ben-Hail D, Porat Z, Juknat A, Kozela E, et al. (2013) Direct modulation of the outer mitochondrial membrane channel, voltage-dependent anion channel 1 (VDAC1) by cannabidiol: a novel mechanism for cannabinoidinduced cell death. Cell death \& disease 4: e949.

89. Aso E, Ferrer I (2014) Cannabinoids for treatment of Alzheimer's disease: moving toward the clinic. Front Pharmacol 5: 37.

90. Sil'kis IG (2002) Possible mechanism of cannabinoid-mediated modulation of signal transduction through the basal ganglia. Rossiiskii fiziologicheskii zhurnal imeni IM Sechenova / Rossiiskaia akademiia nauk 88: 144-157.

91. Pryce G, Riddall DR, Selwood DL, Giovannoni G, BakerD (2014) Neuroprotection in Experimental Autoimmune Encephalomyelitis and Progressive Multiple Sclerosis by Cannabis-Based Cannabinoids. J Neuroimmune Pharmacol

92. Moreno-Martet M, Espejo-Porras F, Fernandez-Ruiz J, de Lago E (2014) Changes in endocannabinoid receptors and enzymes in the spinal cord of SOD1(G93A) transgenic mice and evaluation of a Sativex((R)) -like combination of phytocannabinoids: interest for future therapies in amyotrophic lateral sclerosis. CNS Neurosci Ther 20: 809-815.

93. England TJ, Hind WH1, Rasid NA1, O'Sullivan SE1 (2015) Cannabinoids in experimental stroke: a systematic review and meta-analysis. J Cereb Blood Flow Metab 35: 348-358.

94. Fernández-Ruiz J, Moreno-Martet M, Rodríguez-Cueto C, Palomo-Garo C Gómez-Cañas M, et al. (2011) Prospects for cannabinoid therapies in basal ganglia disorders. Br J Pharmacol 163: 1365-1378.

95. Biegon A (2004) Cannabinoids as neuroprotective agents in traumatic brain injury. Curr Pharm Des 10: 2177-2183.

96. Stella N (2010) Cannabinoid and cannabinoid-like receptors in microglia, astrocytes, and astrocytomas. Glia 58: 1017-1030. 